Western University

Scholarship@Western

Department of Economics Research Reports

Economics Working Papers Archive

1985

\title{
Financial Intermediation, Business Failures, and Real Business Cycles
}

Stephen D. Williamson

Follow this and additional works at: https://ir.lib.uwo.ca/economicsresrpt

Part of the Economics Commons

Citation of this paper:

Williamson, Stephen D.. "Financial Intermediation, Business Failures, and Real Business Cycles." Department of Economics Research Reports, 8515. London, ON: Department of Economics, University of Western Ontario (1985). 
ISSN : 0318-725X

ISBN : 0-7714-0696-7

\section{RESFARCH REPORT 8515}

F MNANC IAL INTERMEDIATION, BUS INESS

FAILURES, AND REAL BUSINESS CYCLES

Stephen D. Williamson

Queen's University and Department of Economics, University of Western

Ontario, London, Ontario, N6A 5C2

Revised November, 1985

Departmeat of Economics Library

DEC $17 \quad 1985$

University of Westem Ontario 
FINANCIAL INTERMEDIATION, BUSINESS FAILURES, AND

REAL BUSINESS CYCLES

\author{
Stephen D. Williamson* \\ Queen's University and \\ Department of Economics \\ University of Western Ontario \\ London, Ontario \\ N6A $5 C 2$
}

Revised November, 1985

* The author wishes to thank the following for helpful comments and suggestions: Scott Freeman, Zvi Hercowitz, Peter Howitt, Greg Huffman, and seminar participants at the Bank of Canada, Queen's University and the University of Western Ontario. Any remaining errors are my own. 
In this paper a general equilibrium business cycle model is constructed which, when subjected to real disturbances, mimics observed qualitative comovements among real output, money, business failures, risk premia, intermediary loans, and prices. In contrast, monetary cycles in the model generate several inconsistencies with empirical evidence, thus providing support for real business cycle theory at the expense of monetary theories of the business cycle. Financial intermediation arises endogenously in the model, and a credit supply mechanism acts in tandem with an intertemporal substitution effect to cause fluctuations in real output. 


\section{Introduction}

Much recent work in business cycle theory accepts as a starting point Robert Lucas' dictum (Lucas (1981), p. 218) that "with respect to the qualitative behavior of comovements among [economic time] series, business cycles are all alike." A business cycle model's success can then be measured by the extent to which it can mimic these observable comovements, without violating other empirical observations, such as those concerning the behavior of individuals. Given the kind of discipline imposed on competitive general equilibrium business cycle models in the form of optimizing behavior and rational expectations, these models might be judged, on the basis of the above criteria, to have been quite successful.

In the literature, surveyed in Prescott (1983), we can identify two types of equilibrium business cycle models. In the first, the business cycle is caused by monetary shocks in an environment with imperfectly informed economic agents. The only model of this type which contains a full description of the economic environment, including preferences, endowments, and technology, is that of Lucas (1972). 1 Models of the second type have been characterized as "real business cycle" models. Here, business cycles are caused by changes in intertemporal production opportunities, rather than by monetary shocks. The important elements of real business cycle models are: 1) There exist production lags which may differ across industries.

2) Production occurs in at least two different sectors. 3) Intertemporal substitution, in some form, is a key feature. 
Some real business cycle models, such as Kydland and Prescott (1982) and King and Plosser (1983), abstract entirely from monetary factors. However,. for real business cycle theory to be successful, it must not only explain the comovements among real variables, but must also explain the observed comovements among money, credit, the price level, and real variables. King and Plosser (1984) attempt to do just this, using a model where real disturbances generate observed money-output correlations due to the endogenous response of the banking system to such disturbances. Observed money-output correlations might also be generated by real disturbances through a policy-induced response of outside money, as in Tobin (1970) and Litterman and Weiss (1985). However, King and Plosser provide some empirical evidence that much of the correlation of money with output is due to correlation between inside money and output.

In this paper, we construct an equilibrium-business cycle model which is capable of explaining observed comovements among time series of real output, the price level, intermediary loans, deposits and monetary aggregates. A novelty in the paper is an explanation of the observed comovements among business failures, risk premia, and other aggregate variables. In particular, real disturbances in the model, in the form of changes in the riskiness of investment projects, produce business cycles with the following features:

1) Real output is serially correlated.

2) Increases in intermediary loans and in a nominal monetary aggregate lead increases in output, in the sense of Granger-causation.

3) Decreases in risk premia lead increases in real output.

4) Business failures and real output are negatively correlated.

5) The price level and real output are positively correlated. 
6) The economy exhibits Phillips curve correlations; i.e., unanticipated inflation and real output are positively correlated.

In spite of the above, in particular features 2 and 6 , a one-time unanticipated increase in outside money in the model is neutral. However, monetary disturbances can induce cyclical behavior in the model, if expected rates of return depend on the current money supply. In the model, an increase in expected rates of return leads to increases in current employment and output, and to a decrease in current intermediary loans and an increase in future business failures. This is clearly inconsistent with what we observe. The model therefore lends support to real business cycle theory at the expense of monetary theories of the business cycle.

of particular importance is that our model displays features 5 and 6. In the model of King and Plosser (1984), where an ad-hoc demand function for currency is appended to the model to generate comovements of the price level with other variables, output and the price level may be negatively correlated. of course, the fact that an equilibrium model could explain "Phillips curve" correlations was responsible for much of the interest in Lucas (1972).

As in King and Plosser (1984), observed money-output correlations are generated through the endogenous response of inside money to exogenous disturbances. However, in contrast to $\mathrm{King}$ and Plosser, there is an explicit role for financial intermediation in our model, similarities to which can be found in the work of Boyd and Prescott (1985), Diamond (1984) and Williamson (1985). Asymmetrically informed lenders and borrowers and costly monitoring, imply that financial intermediation emerges as the dominant vehicle for carrying out borrowing and lending. In addition, these intermediaries write 
debt contracts with borrowers, so that monitoring costs can be interpreted as costs of bankruptcy, incurred when borrowers default.

Costs of bankruptcy and the activities of financial intermediaries have been cited by Bernanke $(1981,1983)$ as important factors in the propagation of business cycles. In our model, costs of bankruptcy are a critical part of the mechanism by which real disturbances cause business cycles. In fact, in the absence of monitoring costs, changes in the riskiness of investment projects would not generate business cycles in our model, as all agents are risk neutral. With positive monitoring costs, business failures result either from bankruptcy for a "firm" that obtains a loan and receives a low return on investment, or because the firm is denied credit. There is a credit supply effect in the model which we might term "credit rationing," in the sense that some would-be borrowers do not receive loans in equilibrium, in spite of the fact that these agents would be willing to pay higher-than-market interest rates to receive loans. Such "credit rationing" equilibria are studied in Keeton (1979), Stiglitz and Weiss (1981), and Williamson (1984, 1985). 2 Though "credit rationing" may be a feature of equilibrium in our model, this does not appear to imply anything in particular about how the monetary authority should conduct its affairs.

The credit supply mechanism acts in the model in tandem with an intertemporal substitution mechanism to produce cycles in real output, though many of the above-listed comovements in aggregate variables can be generated without an intertemporal substitution effect. Our model is similar in this sense to Smith (1985), since Smith's business cycle model also makes use of a contracting framework and produces business cycle behavior without intertemporal substitution. However, our model does not contain adverse 
selection phenomena, as does Smith (1985).

As in Lucas (1972), Sargent and Wallace (1982) and Freeman (forthcoming), we make use of the overlapping generations framework to motivate, from first principles, a demand for unbacked government liabilities. The model also includes intragenerational heterogeneity so as to permit trade in inside assets.

The remainder of the paper is organized as follows. In the second section the model is constructed, while in section 3 we characterize a stationary monetary equilibrium for the model, and demonstrate that the set of parameters and functional forms for which an equilibrium exists is non-empty. Analyses of a real business cycle and of a monetary cycle are carried out in Sections 4 and 5, respectively. The last section is a sumary and conclusion.

\section{The Mode1}

This is a model of an overlapping generations economy with intragenerational heterogeneity. This structure permits the coexistence of inside assets and valued, unbacked government liabilities.

At each time $t=1,2, \ldots, \infty$, a countable infinity of two-period-lived agents are born. Let $d$ denote an agent's type, where $d=1,2$. If at any time $t$ we were to draw an agent at random, then $\operatorname{Pr}[$ agent is young] $=\operatorname{Pr}$ [agent is old] $=1 / 2, \operatorname{Pr}[d=1]=\alpha$ and $\operatorname{Pr}[d=2]=1-\alpha$, where $0<\alpha<1$.

Each type 1 agent born at time $t$ maximizes the expected value of $U\left(c_{t}, l_{t}, c_{t+1}\right)$ where $c_{t}$ is consumption at time $t$, and $\ell_{t}$ is leisure consumed at time $t$. The consumption good is perishable between periods.

We have:

$$
u\left(c_{t}, l_{t}, c_{t+1}\right)=v\left(c_{t}, l\right)+c_{t+1}
$$


In equation $(2.1)$, the function $v(\cdot, \cdot)$ is strictly concave and twice differentiable. We assume that first-period consumption and leisure are . normal goods, ${ }^{3}$ i.e.,

$$
\left.\begin{array}{l}
v_{11}-v_{12}<0 \\
v_{22}-v_{12}<0
\end{array}\right\}
$$

Type 1 agents are each endowed with $h$ units of labor time in the first period of life. Each unit of labor time supplied produces one unit of the consumption good, i.e., the real wage is technologically fixed at unity.

Type 2 agents consume only in the second period of life, and maximize the expected value of consumption. Each type 2 agent has access to an investment project which produces a random return $\tilde{w}$ in period $t+1$ with an input of 1 unit or more of the consumption good in period $t$, and produces zero units otherwise. Returns are independent and identically distributed across type 2 agents in a given generation, according to the probability density function $f(\cdot)$, which is positive and differentiable on $[0, \bar{w}]$. We assume that $E[\tilde{w}]>1$, where $E$ is the expectations operator. Though all agents know $f(\cdot)$, the return on a given investment project can be observed without cost, ex post, only by the type 2 agent who operates the project. other agents must incur a cost of $\gamma$ units of the consumption good, expost, to observe the return on the project. Each type 2 agent's monitoring cost is costlessly observable to all when investment decisions are made and monitoring costs are independent of subsequent returns. Monitoring costs differ across type 2 agents in a given generation, in that if we were to draw an agent at random at time $t$, then 


$$
\operatorname{Pr}\left[Y \leq Y^{\prime} \mid d=2\right]=\int_{0}^{1} g(u) d u
$$

The probability density function $g(\cdot)$ is positive on $[0, \infty)$. Let $F(\cdot)$ and $G(\cdot)$ denote the distribution functions corresponding to $f(\cdot)$ and $g(\cdot)$ respectively.

At time 1, there is a countable infinity of old agents, each endowed with $\mathrm{H}$ units of fiat money. If we draw an agent at random at time 1 , then $\operatorname{Pr}$ [agent is young] $=1 / 2$. Old agents at time $I$ supply fiat money inelastically so as to maximize consumption.

Since there is a countable infinity of agents in each generation, we express aggregate variables in per capita terms, making use of the specified probabilities of drawing an agent of a particular type from the population. This device is used in Boyd and Prescott (1985). The reason for taking this approach here, and for its use by Boyd and Prescott, will be evident when we discuss intermediation in the model.

Type 1 agents can consume in the second period of life either by acquiring fiat money when young or by lending to type 2 agents. The contracts which are set up to carry out intertemporal trade between type 1 and type 2 agents will, optimally, serve to economize on the costs of monitoring borrowers while giving these borrowers the incentive to truthfully report their project returns. One such optimal arrangement involves having all lending done by large multi-agent intermediaries which issue certain return deposit liabilities to type 1 agents and write standard debt contracts with type 2 agents. By a standard debt contract, we mean a contract that specifies that in "non-default" states the borrower will make a fixed payment to the lender, while in default states it is infeasible for the borrower to make the fixed payment, and $100 \%$ of the recoverable return on the project goes to 
the lender. Such contracts are derived optimally in Gale and Hellwig (1984), Diamond (1984), and Williamson (1984, 1985).

To show that the above contracting arrangement is indeed optimal, we first show that, if we ignore incentive and resource constraints within a finite-sized financial intermediary, then debt contracts between this intermediary and a group of borrowers are optimal. Second, we show that as the size of the intermediary becomes large, in the limit the incentive and resource constraints become non-binding. Lenders and borrowers must then be at least as well off with large intermediaries and debt contracts as with small intermediaries and whatever contracting arrangement would exist in this case with more constraints. Small intermediaries must also dominate bilateral contracting, since such an arrangement would involve duplication of monitoring costs or because the size of an investment project and per capita savings are mismatched.

Given that all agents are risk neutral with respect to second period consumption realizations, and since uncertainty in the model will affect only second period consumption, all information affecting a generation $t$ agent's decisions can be summarized in the time $t$ expected gross rate of return on savings which we will denote by $r_{t}$ (to be determined endogenously). In an equilibrium where fiat money is valued, all assets including fiat money must yield an expected return at time $t$ of $r_{t}$. Then, given $r_{t}$, each type 1 agent born at time $t$ will choose to save $s\left(r_{t}\right)$. Type 1 agents will be indifferent in equilibrium concerning the composition of their portfolios. Suppose now that $k$ type 1 agents form an intermediary, each agreeing to deposit $s_{d}$ units of the consumption good with the intermediary, where $s_{d} \leq s\left(r_{t}\right)$. The intermediary members agree to fund $\mathrm{ks}_{\mathrm{d}}$ investment projects owned by type 2 
agents, with s chosen so that $\mathrm{ks}_{\mathrm{d}}$ is an integer. The intermediary then writes contracts with type 2 agents to fund projects, and divides the time $t+1$ proceeds equally among its members. We suppose that intermediary members can costlessly observe monitoring by other members along with the results of this monitoring, so that we ignore the incentive constraints required for the truthful reporting of monitoring to other intermediary members.

Without loss of generality, assume that the intermediary writes identical contracts with type 2 agents having identical monitoring costs, $\gamma$. These contracts need to specify when monitoring will occur and the payments to be made from borrower to lender given what is observed in each state. Contracts must be incentive compatible, and the joint consumption of the intermediary coalition must be nonnegative in all states. If we ignore this last constraint, then we can show, as we do in the appendix, that a standard debt contract is optimal, i.e., if the return on the project, $w<x$, then the intermediary monitors the borrower and the payment to the intermediary is $w$, while if $w \geq x$, then the borrower's payment is $x$ and monitoring does not occur. We can then interpret $x$ as an interest payment, the state when monitoring occurs as bankruptcy, and the monitoring cost, $\gamma$, as a cost of bankruptcy. Here, $\mathrm{x}$ satisfies:

$$
\begin{aligned}
& \max \int_{x}^{\bar{w}}(w-x) f(w) d w \\
& \text { subject to: } \int_{0}^{x}(w-\gamma) f(w) d w+x(1-F(x)) \geq r_{t}
\end{aligned}
$$

If we let $\pi(x, y)$ denote the expected return to the intermediary as a function of $x$ and $Y$, 


$$
\pi(x, y)=\int_{0}^{X}(w-\gamma) f(w) d w+x(1-F(x))
$$

then $\pi(0, y)=0$, and $\pi(x, y)$ is continuous in $x$. Therefore the constraint in (2.3) will be binding for type 2 agents who receive loans, as the objective function in (2.3) is decreasing in $x$, so that if $x^{*}$ solves $(2.3)$ and $\pi\left(x^{*}, \gamma\right)>r_{t}$, there must be some $x^{* \star}<x^{*}$ such that $\pi\left(x^{\star *}, \gamma\right) \geq r_{t}$. Therefore $x^{\star}$ cannot solve (2.3), a contradiction.

Now suppose that the intermediary replicates itself $\mathrm{n}$ times. That is, the number of type 1 agents in the intermediary coalition is nk, and the intermediary makes loans to nks type 2 agents. If $\tilde{R}_{i}$ is the payment received by the intermediary from the $i^{\text {th }}$ type 2 agent, $i=1,2, \ldots, n k s$, then $E\left[\tilde{R}_{\dot{i}}\right]=r_{t}$ for all $i$. Therefore, as $\mathbf{n}$ grows large, the probability limit of the return received by each depositor with the intermediary is

$$
\operatorname{plim}_{n \rightarrow \infty}\left[\frac{1}{n_{d}} \sum_{i=1}^{\text {nks }} \stackrel{\mathrm{R}}{\mathrm{d}}_{i} \quad\right]=r_{t}
$$

by the weak law of large numbers.

Large intermediaries can then guarantee each depositor (intermediary member) a certain return of $r_{t}$, and the nonnegativity constraint on joint consumption becomes nonbinding in the limit. Also, if the intermediary can guarantee depositors a certain return, then there need be no monitoring of the intermediary by depositors, i.e., with a finite-sized intermediary, the return to depositors must necessarily be uncertain, which then creates an incentive problem within the intermediary. Contracts must be set up subject to incentive constraints which would require some monitoring of the intermediary 
by its depositors. Therefore, since large scale intermediation removes both the nonnegativity constraint on consumption and costly monitoring within the intermediary, large intermediaries must make all participants at least as well off as they would be with whatever financial contracting arrangements would be optimal subject to the additional constraints under small scale intermediation. Note also that infinite-sized intermediaries need not set constraints on the size of deposits so as to satisfy the integer constraint on loans. In equilibrium intermediaries will be indifferent concerning deposit size, and depositors will be indifferent concerning the composition of their portfolios. 4

The observable features of intermediation here which correspond to empirical observations are:

1) Intermediaries diversify on both sides of the balance sheet, i.e., they lend to a large number of borrowers, and they have a large number of depositors.

2) Their liabilities have characteristics different from their assets.

3) They write debt contracts with borrowers.

As in Boyd and Prescott (1985), Diamond (1984) and Williamson (1985), diversification is important to the role played by intermediation, in spite of universal risk neutrality. The nonnegativity constraint on consumption plays an important role here as it does in Boyd and Prescott, and as in Diamond's model, intermediation performs a delegated monitoring role. In the model of Williamson (1985), intermediaries write debt contracts with borrowers, as is the case here.

Using integration by parts, we can rewrite (1.4) as: 


$$
\pi(x, y)=x-\int_{0}^{x} F(t) d t-\gamma F(x)
$$

Equation (2.5) allows an interpretation of the negative of the sum of the second and third terms on the right-hand side as a risk premium. Though type 1 agents are risk neutral, borrower bankruptcy and debt contracts make these agents effectively risk averse. Note that $\int_{0}^{x} F(t) d t$ increases as the riskiness of investment projects increases, in the sense of Rothschild and Stiglitz (1970), while $Y F(x)$ is the expected cost of monitoring to the intermediary.

While the expected return to the borrower is a decreasing function of $x$, the expected return to the lender is not monotone increasing in $x$.

Differentiating (2.5) with respect to $x$, we get:

$$
\mathbb{x}_{1}(x, y)=1-F(x)-\gamma f(x)
$$

Therefore $\pi_{1}(x, y)<0$ for at least some $x \in[0, \bar{w}]$. We assume that:

$$
f(x)+y f^{\prime}(x)>0 \text { if } \pi(x, y) \geq 0
$$

i.e., for that part of the expected return function which is nonnegative, the function is assumed to be concave in $x$. Note that $\pi(x, \gamma)$ is decreasing in $Y$. Therefore, if we define the function $\pi^{*}(\gamma)$ by

$$
\Pi^{\star}(\gamma)=\max \left\{\max _{x} \Pi(x, \gamma), 0\right\}
$$

then $d \pi^{*}(\gamma) / d \gamma<0$ for $\pi^{*}(\gamma)>0$ by the envelope theorem, i.e., the maximum expected return a lender can earn by investing in a project decreases as the monitoring cost increases. 


\section{Stationary Honetary Equilibrium}

In this section, we proceed to characterize a stationary monetary equilibrium for the model presented in Section 2, and to show by way of example that the set of functional forms and parameter values for which an equilibrium exists is nonempty.

If we let $s_{t}$ denote savings by a representative type 1 agent born at time $t$, then this agent solves the following problem:

$$
\begin{aligned}
& \max _{t}\left\{v_{t}\left\{c_{t}, e_{t}\right)+c_{t+1}\right\} \\
& \text { subject to: }\left\{\begin{array}{l}
c_{t}+l_{t}+s_{t}=h \\
c_{t+1}=r_{t} s_{t} \\
c_{t}, c_{t+1}, s_{t} \geq 0 \\
0 \leq \ell_{t} \leq h
\end{array}\right.
\end{aligned}
$$

where $r_{t}$ was defined in the previous section to be the expected gross rate of return faced by agents at time $t$. Assuming an interior solution with $s_{t}>0$, the following first-order conditions characterize a solution to ( 3.1$)$ :

$$
\begin{aligned}
& -v_{1}\left(h-l_{t}-s_{t}, l_{t}\right)+v_{2}\left(h-l_{t}-s_{t}, l_{t}\right)=0 \\
& -v_{1}\left(h-l_{t}-s_{t}, l_{t}\right)+r_{t}=0
\end{aligned}
$$

where $v_{i}\left(c_{t}, l_{t}\right)$ is the derivative with respect to the $i^{\text {th }}$ argument of $v(\bullet, \bullet)$, evaluated at $\left(c_{t}, l_{t}\right)$.

From the analysis of the previous section, we know that, given the market expected return, $r_{t}$, there will be some monitoring cost, $\gamma_{t}^{*}$, such that $\pi^{*}(\gamma) \geq r_{t}$ for $\gamma \leq \gamma_{t}$, and $\pi^{*}(\gamma)<r_{t}$ for $\gamma>\gamma_{t}^{*}$. Type 2 agents 
with $Y \leq Y_{t}^{*}$ will receive loans in equilibrium, while those with $Y>\gamma_{t}^{*}$ will not receive loans. While all mutual gains from trade are exhausted in equilibrium, some would-be borrowers do not receive loans, in spite of the fact that they would be willing to pay higher-than-market interest rates in order to avoid consuming zero in the following period. This state of affairs might be termed "credit rationing". If such phenomena were observed in the real world, ${ }^{5}$ then some might be tempted to argue that this was evidence of some sort of "disequilibrium". Clearly, this is not the case here. As we will further argue later in the paper, such "credit rationing" phenomena imply no obvious role for government intervention or stabilization policy, at least in this model.

The mechanism which generates "credit rationing" in this model is similar to that in Williamson $(1984,1985)$, though here we have heterogeneity among the group of borrowers. Note that this mechanism, an asymmetry in the payoff functions of lenders and borrowers generated by costly monitoring and ex post asymmetric information, is quite different from that contained in the work of Stiglitz and Weiss (1981). We comment on these differences in more detail elsewhere (see Williamson (1984, 1985)).

Note that borrowers with different monitoring costs pay different interest rates, since $\pi(x, \gamma)=r_{t}$ for all $\gamma$. Since $\pi_{2}<0$, and $\pi_{1}>0$ for $\gamma<\gamma_{t}^{*}$, interest rates increase with monitoring costs among the group of type 2 agents who receive loans. For the type 2 agent who is at the margin, with $\gamma=\gamma^{*}$, we have $\pi^{*}\left(\gamma_{t}^{*}\right)=r_{t}$, or, from $(2.6)$ :

$$
1-F\left(x_{t}^{*}\right)-\gamma_{t}^{*} f\left(x_{t}^{*}\right)=0
$$


where $x_{t}^{*}$ satisfies:

$$
x_{t}^{*}-\int_{0}^{x^{*}} F(t) d t-y_{t}^{*} F\left(x_{t}^{*}\right)=r_{t}
$$

The quantity of loans, equal to the quantity of deposits, is $L_{t}=$ (1- $\alpha) G\left(c_{t}^{*}\right)$. Since savings is held either in the form of deposits or fiat money, equilibrium in the money market implies that

$$
\alpha s_{t}-(1-\alpha) G\left(\gamma_{t}^{*}\right)=p_{t} H
$$

In a stationary monetary equilibrium, $p_{t}=p>0$, for all $t$, since the population is static. We therefore have

$$
\mathbf{r}_{\mathbf{t}}=1
$$

Equations (3.2), (3.3), (3.4), (3.5), (3.6) and (3.7) solve for equilibrium $\ell, s, x^{\star}, r^{*}, p$, and $r$.

An Example

$$
\begin{aligned}
& \text { Let: }\left\{\begin{aligned}
v\left(c_{t}, l_{t}\right) & =\ln c_{t}+\ln l_{t} \\
& \frac{1}{8}, \quad 0 \leq w \leq 8 \\
f(w)= & \text { otherwise }
\end{aligned}\right. \\
& \left\{\begin{array}{cll}
g(\gamma)= & .3 e^{-.3 \gamma}, & c \geq 0 \\
. \cdot & 0, & \text { otherwise }
\end{array}\right.
\end{aligned}
$$

Then (3.2), (3.3) and (3.7) imply that:

$$
\ell_{t}=\frac{1}{r_{t}}=1
$$




$$
s_{t}=h-2 / r_{t}=h-2
$$

Equations (3.4) and (3.5) imply that $x^{\star}=\gamma^{\star}=4$. Therefore,

$$
p=[\alpha(h-2)-(1-\alpha)(.7)] / H
$$

and an equilibrium exists if $p>0$, i.e.,

$$
h>2+\left(\frac{1-\alpha}{\alpha}\right)(.7)
$$

In this example, $70 \%$ of would-be borrowers receive loans in each period $t=1,2, \ldots, \infty$. Since type 1 agents view fiat money and intermediary deposits as perfect substitutes in equilibrium, we can aggregate the two to get a measure of the total nominal quantity of 'money', which we denote by $M$ :

$$
M=\alpha s / p=H\left[\frac{\alpha(h-2)}{\alpha(h-2)-(.7)(1-\alpha)}\right]
$$

The example proves that the set of utility functions, distributions, and parameter values for which a stationary equilibrium with valued fiat money exists is non-empty. 6

\section{A Real Cycle}

Costs of bankruptcy have been cited by Bernanke $(1981,1983)$ as an important propagation mechanism in the business cycle, and in particular as an element which helped to accentuate the downturn during the depression. We want to show that in our model, costs of bankruptcy in conjunction with real shocks to the economy, can in fact cause business cycles in which the comovements among aggregate time series match qualitatively the observed comovements in the data. To show that these bankruptcy costs matter in an 
important way, the real shocks to which the economy is subjected do not produce cycles in the absence of costs of bankruptcy.

The economy can be in one of two states at any time $t, s_{t}=1,2$. We assume without loss of generality that $s_{1}=1$. The state at time $t$ becomes known to all after time $t-1$ decisions are made and before generation $t$ agents are born. We assume that $s_{t}$ follows a Markov process, i.e.,

$$
\operatorname{Pr}\left[s_{t}=1 \mid s_{t-1}=i\right]=q_{i}, \quad i=1,2 \text {. }
$$

Here $q_{1} \geq q_{2}$, so that $s_{t}$ is not negatively serially correlated. In states 1 and 2 , the features of the economy are identical to that specified in section 2 , except that in state 2 the probability density function for the return on a given project is $f(w)+\delta k(w)$, where $0<\delta \leq 1$ and $k(\cdot)$ has the following properties:

$$
\begin{array}{ll}
\int_{0}^{\bar{w}} w k(w) d w=0 & \\
f(w)+\delta k(w)>0, & 0 \leq w \leq \bar{w} \\
\int_{0}^{x} k(w) d w \geq 0, & \text { for } 0 \leq x \leq \bar{w} \\
k(w)=0, & \text { for } 1 \leq w \leq x^{*} \\
k(w)=k(1)=0 &
\end{array}
$$

where $k(x)=\int_{0}^{x} k(w) d w$. In state 2 then, investment projects are more risky, in the sense that the state 2 return distribution is arrived at by applying a mean-preserving spread to the state 1 return distribution (see 
Rothschild and stiglitz (1970)). Wote that the mean-preserving spread is carried out in such a way as to affect projects which are funded in a stationary monetary equilibrium in an identical manner.

We look only at time stationary equilibria, i.e., equilibria where prices and quantities depend only on $s_{t}$. We will let subscripts denote states so that, for example, $p_{i}$ is the price of fiat money in state $i$. The expected return faced by agents born in state 1 is then $q_{1}+\left(1-q_{1}\right) p_{2} / p_{1}$ and by agents born in state 2 is $q_{2} p_{1} / p_{2}+1-q_{2}$.

As in Section 2, we can then write down the following equations which characterize an equilibrium.

Type $I$ agents choose $\ell_{i}$ and $s_{i}$ optimally:

$$
\begin{aligned}
& -v_{1}\left(y-l_{i}-s_{i}, l_{i}\right)+v_{2}\left(y-l_{i}-s_{i}, l_{i}\right)=0, \quad i=1,2 \\
& -v_{1}\left(y-l_{1}-s_{1}, l_{1}\right)+q_{1}+\left(1-q_{1}\right) p_{2} / p_{1}=0 \\
& -v_{1}\left(y-l_{2}-s_{2}, l_{2}\right)+q_{2} p_{1} / p_{2}+1-q_{2}=0
\end{aligned}
$$

The interest rate paid by the marginal borrower maximizes the return to the lender, and the expected return on the marginal loan is the market return:

$$
\begin{aligned}
& 1-F\left(x_{1}^{*}\right)-\gamma_{1}^{*} f\left(x_{1}^{*}\right)=0 \\
& 1-F\left(x_{2}^{*}\right)-\delta K\left(x_{2}^{*}\right)-y_{2}^{*}\left[f\left(x_{2}^{*}\right)+\delta k\left(x_{2}^{*}\right)\right]=0 \\
& x_{1}^{*}-\int_{0}^{*} F(t) d t-\gamma_{1}^{*} F\left(x_{1}^{*}\right)=q_{1}+\left(1-q_{1}\right) p_{2} / p_{1}
\end{aligned}
$$




$$
x_{2}^{*}-\int_{0}^{x^{*}}[F(t)+\delta K(t)] d t-\gamma_{2}^{*}\left[F\left(x_{2}^{*}\right)+\delta K\left(x_{2}^{*}\right)\right]=q_{2} p_{1} / p_{2}+1-q_{2}
$$

The money market clears in each state:

$$
\alpha s_{i}-(1-\alpha) G\left(\gamma_{i}^{*}\right)=p_{i}^{H}, \quad i=1,2
$$

To show how aggregate variables depend on $s_{t}$, at least for small $\delta$, we carry out a comparative static analysis about the stationary monetary equilibrium. We totally differentiate equations $(4.1)-(4.8)$, set $\delta=0$ and solve to get:

$$
\begin{aligned}
& \left.\frac{d\left(p_{1} / p_{2}\right)}{d \delta}\right|_{\delta=0}=-\left[(1-\alpha) g\left(\gamma^{*}\right) \int_{0}^{x} K(t) d t\right] /\left\{\left(1-q_{1}+q_{2}\right)\right. \\
& \left.\left[\frac{\alpha F\left(x^{*}\right)\left(-v_{11}+2 v_{12}-v_{22}\right)}{v_{22}^{v_{11}}-v_{12}^{2}}\right]+(1-\alpha) g\left(\gamma^{*}\right)\right] \\
& \left.+F\left(x^{\star}\right)\left[\alpha s-(1-\alpha) G\left(\gamma^{\star}\right)\right]\right\}<0 \\
& \left.\frac{d \gamma_{1}^{*}}{d \delta}\right|_{\delta=0}=\left.\frac{\left(1-q_{1}\right)}{F\left(x^{*}\right)} \frac{d\left(p_{1} / p_{2}\right)}{d \delta}\right|_{\delta=0}<0 . \\
& \left.\frac{d Y_{2}^{*}}{d \delta}\right|_{\delta=0}=\left.\frac{-q_{2}}{F\left(x^{*}\right)} \frac{d\left(p_{1} / p_{2}\right)}{d \delta}\right|_{\delta=0}-\frac{1}{F\left(x^{*}\right)} \int_{0}^{x} k(t) d t<0 \\
& \left.\frac{d l}{d \delta}\right|_{\delta=0}=\left[\frac{v_{11}-v_{21}}{v_{22} v_{11}-v_{12}^{2}}\right]\left[-\left.\left(1-q_{1}\right) \frac{d\left(p_{1} / p_{2}\right)}{d \delta}\right|_{\delta=0}\right]<0
\end{aligned}
$$


$\left.\frac{d l}{d \delta}\right|_{\delta=0}=\left.\left[\frac{v_{11}-v_{21}}{v_{22} v_{11}-v_{12}^{2}}\right] q_{2} \frac{d\left(p_{1} / p_{2}\right)}{d \delta}\right|_{\delta=0}>0$

$\left.\frac{d s}{d \delta}\right|_{\delta=0}=\left[\frac{11+2 v_{12}-v_{22}}{v_{22} v_{11}-v_{12}^{2}}\right]\left[-\left.\left(1-q_{1}\right) \frac{d\left(p_{1} / p_{2}\right)}{d \delta}\right|_{\delta=0}\right]>0$

$\left.\frac{d s}{d \delta}\right|_{\delta=0}=\left.\left[\frac{-v_{11}+2 v_{12}-v_{22}}{v_{22} v_{11}-v_{12}^{2}}\right] q_{2} \frac{d\left(p_{1} / p_{2}\right)}{d \delta}\right|_{\delta=0}<0$

Note that $\left.\frac{d \gamma_{1}^{*}}{d \delta}\right|_{\delta=0}-\left.\frac{d \gamma_{2}^{*}}{d \delta}\right|_{\delta=0}>0$. Therefore, the price of fiat money

is lower and the price level, the quantity of lending, savings, and employment are all higher in state 1 than in state 2 . In equilibrium, type 1 agents are indifferent between holding fiat money and intermediary deposits, since the expected returns to holding the two assets are identical. Therefore, as in the stationary equilibrium, we can aggregate inside and outside money to get:

$$
M_{i}=\alpha s_{i} / p_{i}
$$

Since $s_{1}>s_{2}$ and $P_{1}>p_{2}$, therefore $M_{1}>M_{2}$, i.e., the nominal money supply is higher in state 1 than in state 2 .

Suppose that we consider a type 2 agent with monitoring cost $\gamma$. If $r \leq r_{1}^{*}$ and $r \leq r_{2}^{*}$, then this agent will have her project funded if she is born in state 1 or. in state 2 , and will face a gross loan interest rate of $x_{i}=h_{i}(\gamma)$ in state $i$, where $h_{1}(\gamma)$ and $h_{2}(\gamma)$ satisfy: 


$$
\begin{aligned}
h_{1}(\gamma)-\int_{0}^{h_{1}(\gamma)} F(t) d t-\gamma F\left(h_{1}(\gamma)\right) & =q_{1}+\left(1-q_{1}\right) p_{2} / p_{1} \\
h_{2}(\gamma)-\int_{0}^{h_{2}(\gamma)}[F(t)+\delta K(t)] d t-\gamma\left[F\left(h_{2}(\gamma)\right)+\delta K\left(h_{2}(\gamma)\right]\right. & \\
& =q_{2} p_{1} / p_{2}+1-q_{2}
\end{aligned}
$$

Totally differentiating $(4.9)$ and $(4.10)$ and substituting, we get:

$$
\begin{aligned}
& \left.\frac{d h_{1}(\gamma)}{d \delta}\right|_{\delta=0}-\left.\frac{d h_{2}(\gamma)}{d \delta}\right|_{\delta=0}= \\
& -F\left(x^{*}\right)\left[\frac{\int_{0}^{x} K(t) d t}{1-F(x)-c f(x)}\right]\left[\begin{array}{l}
\left(1-q_{1}+q_{2}\right)\left[\frac{\alpha\left(-v_{11}+2 v_{12}-v_{22}\right)}{v_{22}^{v} 11^{*}-v^{2}}\right] \\
-\left[\alpha s-(1-\alpha) G\left(c^{*}\right)\right]
\end{array}\right]<0
\end{aligned}
$$

I.e., type 2 agents with the same characteristics pay higher interest rates if they are born in state 2 than in state 1 . Therefore, since the probability of defaulting (i.e., the probability of bankruptcy) is $F\left(x_{i}\right)$ if the agent is born in state $i$, the probability that bankruptcy occurs is higher in state 2 . In addition, we can express the agent's state 1 and state 2 risk premia, denoted $\rho_{i}, i=1,2$, as

$$
p_{1}=\int_{0}^{h_{1}(\gamma)} F(t) d t+\gamma F\left(h_{1}(\gamma)\right)
$$




$$
p_{2}=\int_{0}^{h}[F(t)+\delta K(t)] d t+\gamma F\left(h_{2}(\gamma)\right)
$$

Since $h_{1}(\gamma)<h_{2}(\gamma)$ therefore $p_{1}<\rho_{2}$.

In our model we define a business failure to be a state where a type 2 agent in the second period of life consumes zero. This will occur either due to bankruptcy, if the agent received a loan in the previous period, or because the agent did not receive a loan in the previous period. Therefore, for a type 2 agent with monitoring cost $\gamma$,

$$
\operatorname{Pr}\left[\text { failure at } t+1 \mid s_{t}=i\right]= \begin{cases}F\left(h_{i}(\gamma)\right), & c \leq \gamma_{i}^{*} \\ 1, & c>\gamma_{i}^{*}\end{cases}
$$

Therefore, $\operatorname{Pr}\left[\right.$ failure at $\left.t+1 \mid s_{t}=1\right] \leq \operatorname{Pr}$ [failure at $t+1 \mid s_{t}=2$ ] for all $Y$, since $\gamma_{1}^{*}>\gamma_{2}^{*}$. Also, if $\gamma \leq \gamma_{1}^{*}$ and $Y \leq \gamma_{2}^{*}$, then $\operatorname{Pr}$ [failure at $t+1 \mid s_{t}=$ 1] < Pr[failure at $\left.t+1 \mid s_{t}=2\right]$. Therefore, if we let $B_{i}$ denote the number of business failures at $t+1$ if $s_{t}=i$, then $B_{1}<B_{2} \cdot 7$

Let $y_{i j}$ denote real output at time $t$ given that $s_{t}=i$ and $s_{t-1}=j$. Output is made up of two components:

$$
y_{i j}=\theta_{i}+\phi_{j}
$$

where $\theta_{i}$ is output produced in period $t$ with the labor input of type 1 agents, and $\phi_{j}$ is output produced in period $t$ as the result of period $t-1$ investment. Noting that we must net out the quantity of the consumption good absorbed in monitoring when calculating output, we get:

$$
\theta_{i}=\alpha\left(h-l_{i}\right)
$$




$$
\Phi_{i}=(1-\alpha) \int_{0}^{\gamma_{i}^{*}}\left[E[\tilde{w}]-\gamma F\left(h_{i}(\gamma)\right)\right] g(\gamma) d \gamma
$$

since $\ell_{1}<\ell_{2}$, therefore $\theta_{1}>\theta_{2}$. Also,

$$
\begin{gathered}
\phi_{1}-\phi_{2}=(1-\alpha) \int_{0}^{\gamma_{2}^{*}} \gamma\left[F\left(h_{2}(\gamma)\right)-F\left(h_{1}(\gamma)\right)\right] g(\gamma) d \gamma \\
+(1-\alpha) \int_{*}^{\gamma_{1}^{*}}\left[E[\tilde{w}]-\operatorname{cF}\left(h_{1}(\gamma)\right)\right] g(\gamma) d \gamma \\
>0 \\
\gamma_{2}
\end{gathered}
$$

Since $h_{1}(\gamma)<h_{2}(\gamma)$, and

$$
E[\tilde{w}]-\gamma F\left(h_{1}(\gamma)\right)={ }_{h}^{\bar{w}}(\gamma)\left[w-h_{1}(\gamma)\right] f(w) d w+q_{1}+\left(1-q_{1}\right) p_{2} / p_{1}>0
$$

for $Y \leq Y_{1}^{*}$

Now that we know something about how aggregate variables vary in response to changes in project return risk, at least for small changes in risk over the cycle, we can also say something about the characteristics of the limiting joint distribution of these variables. We first calculate limiting probabilities for the occurence of each state, denoted $\Psi_{i}, i=1,2$. We have:

$$
\Psi_{1}=\frac{q_{2}}{1-q_{1}+q_{2}}, \quad \Psi_{2}=\frac{1-q_{1}}{1-q_{1}+q_{2}}
$$


Also, let $\Psi_{i j}$ denote the limiting probability of the occurrence of state $i$ preceded by state $j$. Then

$$
\begin{aligned}
& \Psi_{11}=\frac{q_{1} q_{2}}{1-q_{1}+q_{2}} \quad \Psi_{21}=\Psi_{12}=\frac{q_{2}\left(1-q_{1}\right)}{1-q_{1}+q_{2}} \\
& \Psi_{22}=\frac{\left(1-q_{1}\right)\left(1-q_{2}\right)}{1-q_{1}+q_{2}}
\end{aligned}
$$

Given this information, we can calculate the theoretical large sample variances and covariances among aggregate time series generated by our model. For any two time series, $\left\{a_{t}\right\}_{t=1}^{\infty}$ and $\left\{b_{t}\right\}_{t=1}^{\infty}$, where $a_{t}$ and $b_{t}$ depend only on $s_{t}$, we get:

$$
\operatorname{cov}\left(a_{t}, b_{t-j}\right)=\frac{q_{2}\left(1-q_{1}\right)\left(q_{1}-q_{2}\right)^{j}\left(a_{1}-a_{2}\right)\left(b_{1}-b_{2}\right)}{\left(1-q_{1}+q_{2}\right)^{2}}
$$

Therefore,

$$
\begin{aligned}
& \operatorname{cov}\left(y_{t}, y_{t-j}\right)=\left[q_{2}\left(1-q_{1}\right) /\left(1-q_{1}+q_{2}\right)^{2}\right] \\
& {\left[\left(\theta_{1}-\theta_{2}\right)^{2}\left(q_{1}-q_{2}\right)^{j}+\left(\theta_{1}-\theta_{2}\right)\left(\phi_{1}-\phi_{2}\right)\left[\left(q_{1}-q_{2}\right)^{j+1}+\left(q_{1}-q_{2}\right)^{j-1}\right]\right.} \\
& \left.\quad+\left(\phi_{1}-\phi_{2}\right)^{2}\left(q_{1}-q_{2}\right)^{j}\right], \quad j \geq 1 \\
& \operatorname{var}\left(y_{t}\right)=\left[q_{2}\left(1-q_{1}\right) /\left(1-q_{1}+q_{2}\right)^{2}\right]\left[\theta_{1}-\theta_{2}\right)^{2} \\
& \left.\quad+2\left(\theta_{1}-\theta_{2}\right)\left(\phi_{1}-\phi_{2}\right)\left(q_{1}-q_{2}\right)+\left(\phi_{1}-\phi_{2}\right)^{2}\right]
\end{aligned}
$$




$$
\begin{aligned}
\operatorname{cov}\left(y_{t}, a_{t-j}\right)= & {\left[q_{2}\left(1-q_{1}\right) /\left(1-q_{1}+q_{2}\right)^{2}\right]\left(a_{1}-a_{2}\right) } \\
& {\left[\left(\theta_{1}-\theta_{2}\right)\left(q_{1}-q_{2}\right)^{j}+\left(\phi_{1}-\phi_{2}\right)\left(q_{1}-q_{2}\right)^{j-1}\right], } \\
& j \geq 1 \\
\operatorname{cov}\left(y_{t}, a_{t+j}\right)= & {\left[q_{2}\left(1-q_{1}\right) /\left(1-q_{1}+q_{2}\right)^{2}\right]\left(a_{1}-a_{2}\right) } \\
& {\left[\left(\theta_{1}-\theta_{2}\right)\left(q_{1}-q_{2}\right)^{j}+\left(\phi_{1}-\phi_{2}\right)\left(q_{1}-q_{2}\right)^{j+1}\right] } \\
& j \geq 0
\end{aligned}
$$

Therefore, if $q_{1}>q_{2}$ (serially correlated disturbances) given that $M_{1}>M_{2}$, $p_{1}<p_{2}, B_{1}<B_{2}, \theta_{1}>\theta_{2}$ and $\phi_{1}>\phi_{2}$, we conclude from (4.13)-(4.17) that: money and output are positively correlated at all leads and lags; output has a positive autocovariance at all lags with exponential decay after lag 1; output and the price level are positively correlated at all leads and lags; output and business failures are negatively correlated at all leads and lags.

In the case where $q_{1}=q_{2}$ (serially uncorrelated disturbances), the signs of the contemporaneous covariances are the same as for the case with serially correlated disturbances, but the covariances of output with other variables having a lead or lag of more than one are zero. Real output and money lagged one period are positively correlated, while business failures and output lagged one period are negatively correlated. Also, real output is positively serially correlated, though its autocovariance function is non-zero only for $\mathbf{j}=\mathbf{0}$ and $\mathbf{j = 1}$

From (4.16) and (4.17), the contemporaneous covariance of real output with the change in the price of fiat money is: 


$$
\begin{aligned}
& \operatorname{cov}\left(y_{t}, p_{t}-p_{t-1}\right)=\operatorname{cov}\left(y_{t}, p_{t}\right)-\operatorname{cov}\left(y_{t}, p_{t-1}\right) \\
& =\left[\frac{q_{2}\left(1-q_{1}\right)\left(p_{1}-p_{2}\right)}{1-q_{1}+q_{2}}\right]\left[\left(\theta_{1}-\theta_{2}\right)-\left(\phi_{1}-\phi_{2}\right)\right] .
\end{aligned}
$$

This covariance is of indeterminate sign, and it may therefore appear that the model may generate an inconsistency with observed "Phillips curve" correlations. However, if we look instead at the covariance of the unanticipated change in $p_{t}$ with real output, 8 we get:

$$
\begin{gathered}
\operatorname{cov}\left(y_{t}, p_{t}-E_{t-1} p_{t}\right)=q_{2}\left(1-q_{1}\right)\left(\theta_{1}-\theta_{2}\right)\left(p_{1}-p_{2}\right) \\
\cdot\left(1-q_{2}+q_{1}\right) /\left[1-q_{1}+q_{2}\right]^{2} \\
<0
\end{gathered}
$$

Here $\mathrm{E}_{t-1}$ is the expectations operator conditional on information available at time $t-1$. This is consistent with the effect captured in the "Lucas supply function" (see Lucas (1973)), though it occurs here for a quite different reason, as agents in our model have no problem distinguishing real from nominal disturbances. Note also that real output and unanticipated money are positively correlated.

$$
\begin{aligned}
\operatorname{cov}\left(y_{t}, M_{t}-E_{t-1} M_{t}\right) & =q_{2}\left(1-q_{1}\right)\left(\theta_{1}-\theta_{2}\right)\left(H_{1}-H_{2}\right) \\
\cdot & \left(1-q_{2}+q_{1}\right) /\left(1-q_{1}+q_{2}\right)^{2} \\
> & 0
\end{aligned}
$$


Suppose now that a time series econometrician were to perform bivariate "causality" tests on the time series generated by our model. For example, suppose this econometrician were given time series on money and real output and ran the following regressions:

$$
\begin{aligned}
& y_{t}=\beta_{10}+\beta_{11} y_{t-1}+\beta_{12} M_{t-1} \\
& M_{t}=\beta_{20}+\beta_{21} y_{t-1}+\beta_{22}{ }^{M}-1
\end{aligned}
$$

One test for unidirectional Granger causality running from money to income (see Geweke, Meese and Dent (1983)) is a test of the null hypothesis, $\mathrm{H}_{0}: \beta_{12} \neq 0, \beta_{21}=0$. Let $\mathrm{n}$ denote the sample size, and let a ${ }^{\wedge} \operatorname{denote} a$ least squares estimate. Then,

$$
\begin{aligned}
& \operatorname{plim}_{n \rightarrow \infty} \hat{\beta}_{11}=\frac{\sigma_{x}^{2} \sigma_{y y}-\sigma_{M y}^{\sigma} \sigma_{-1}}{\sigma_{y}^{2} \sigma_{M}^{2}-\sigma_{M y}^{2}} \\
& \operatorname{plim}_{n \rightarrow \infty} \hat{\beta}_{12}=\frac{\sigma_{y}^{2} \sigma H-\sigma_{M y}^{\sigma} \sigma_{-1}}{\sigma_{y}^{2} \sigma_{M}^{2}-\sigma_{M y}^{2}} \\
& \operatorname{plim}_{n \rightarrow \infty} \hat{\beta}_{21}=\frac{\sigma_{M}^{2} \sigma y-\sigma_{M y}^{\sigma} \sigma_{M M}}{\sigma_{y}^{2} \sigma_{M}^{2}-\sigma_{M y}^{2}}
\end{aligned}
$$




$$
\operatorname{plim}_{n \rightarrow \infty} \hat{\beta}_{22}=\frac{\sigma_{y}^{2} \sigma_{M H}-\sigma_{M y}^{\sigma}{ }_{M y}-1}{\sigma_{y}^{2} \sigma_{M}^{2}-\sigma_{M y}^{2}}
$$

where $\sigma_{\mathrm{Hy}}=\operatorname{cov}\left(\mathrm{H}_{t}, \mathrm{y}_{t}\right), \sigma_{\mathrm{H}}^{2}=\operatorname{var}\left(\mathrm{H}_{t}\right), \sigma_{\mathrm{Hy}-1}=\operatorname{cov}\left(\mathrm{H}_{t}, \mathrm{y}_{\mathrm{t}-1}\right)$, and $\sigma_{\mathrm{YM}-1}=$ $\operatorname{cov}\left(y_{t}, M_{t-1}\right)$. Using $(4.13)-(4.17)$ to substitute in $(4.22)-(4.25)$, we get:

$$
\begin{aligned}
& \operatorname{plim}_{n \rightarrow \infty} \hat{\beta}_{11}=0 \\
& \operatorname{plim}_{n \rightarrow \infty} \dot{\beta}_{12}=\frac{\left(\theta_{1}-\theta_{2}\right)\left(q_{1}-q_{2}\right)+\left(\phi_{1}-\phi_{2}\right)}{\left(M_{1}-q_{2}\right)}>0 \\
& \operatorname{pim}_{n \rightarrow \infty} \hat{\beta}_{21}=0 \\
& \operatorname{plim}_{n \rightarrow \infty} \hat{\beta}_{22}=q_{1}-q_{2} \geq 0
\end{aligned}
$$

Therefore, given a large enough sample, unidirectional Granger causality running from money to income would not be rejected. Note that this is the case even if $q_{1}=q_{2}$, and the real disturbances are not serially correlated. We would obtain identical qualitative results if we replaced money by the quantity of loans or by risk premia for borrowers with the same characteristics, i.e., with a large enough sample, we would find causality running from loans to output and from risk premia to output. Note that there are two mechanisms in the model which cause real output to fluctuate. The first is an intertemporal substitution mechanism, which is common to most equilibrium business cycle models, i.e., an increase 
in the anticipated real rate of return causes type 1 agents to consume less leisure, and employment and output increase. The second mechanism is a credit supply effect, or what might be interpreted as a "rationing" effect, in which a restriction on the number of loans extended by intermediaries in the current period reduces next period's output. Even if there were no intertemporal substitution effect in the model, i.e., if $\theta_{1}=\theta_{2}$, the model would still generate most of the correlations cited above. The exceptions are: 1) employment would not vary over the cycle; 2) unanticipated inflation and real output would be uncorrelated and 3) unanticipated money and real output would be uncorrelated.

To sumnarize the results of this section, we have constructed a general equilibrium model where stochastic shifts in the riskiness of investment projects generate business cycles with the following properties:

1) Real output is positively serially correlated.

2) A nominal monetary aggregate and real output are positively correlated, as are loans and real output.

3) Output and the price level are positively correlated.

4) Output and business failures are negatively correlated.

5) Output and unanticipated money are positively correlated.

6) Output and unanticipated inflation are positively correlated.

7) Money Granger - causes output.

All of the above are consistent with what we observe. Features, 1, 2, 3 and 6 are well known (see Lucas (1981)), while feature 7 could not be rejected for U.S. data by sims $(1972,1980)$. Evidence for feature 5 comes from the work of Barro (1977) and Mishkin (1982). The evidence for feature 4 is not as well documented, beyond casual empiricism. However, see Fiedler (1971) for 
evidence that measures of credit risk move counter-cyclically, and Moore and Klein (1967) for evidence that consumer credit quality is procyclical.

A unique feature of this model among real business cycle models is that it exhibits features 3 and 6 . In the framework of King and Plosser (1984), real output and the price level may be negatively correlated in a real business cycle, though King and Plosser attempt to argue that this is consistent with the data, supporting this with regressions which show that real output and inflation are negatively correlated. In our model, output and inflation may be negatively correlated, in spite of feature 3 . As well, the model exhibits Phillips curve correlations when we correct for anticipated inflation (feature 6).

The evidence in Sims $(1972,1980)$ as well as Friedman and Schwartz (1963) supports the existence of unidirectional Granger causality running from money to income for U.S. data, as is consistent with feature 7 . In spite of this, however, a one-time unanticipated increase in the stock of fiat money, carried out through transfers to old agents, would only increase the price level proportionately, and would have no effect on any real variables. 9 This might appear doubly surprising given feature 5. What all this helps to illustrate, is that aggregating assets into something called "money", and then drawing inferences concerning the effects of changes in outside money from endogenously-generated time series correlations of "money" with other variables, can prove hazardous.

We might ask, given features 2,5 and 6 , whether this theory might be observationally equivalent to the Lucas-type monetary theories of the business cycle. Lucas' theory predicts that real output should be correlated only with unanticipated money, and that anticipated money and output should be 
uncorrelated. Suppose that we were to run a regression of the form:

$$
y_{t}=\beta_{0}+\beta_{1}\left(M_{t}-E_{t-1} M_{t}\right)+\beta_{2} E_{t-1} M_{t}
$$

where $E_{t-1}$ is the expectations operator conditional on all information available at time $t-1$. Then using the methods of Barro (1977) and given a sample of size $n$, our estimates $\hat{\beta}_{1}$ and $\hat{\beta}_{2}$ would have the following probability limits:

$$
\begin{aligned}
& \operatorname{pim}_{n \rightarrow \infty} \hat{\beta}_{1}=\frac{\left(1-q_{1}+q_{2}\right)\left[\left(\theta_{1}-\theta_{2}\right)+\left(\phi_{1}-\phi_{2}\right)\left(q_{1}-q_{2}\right)\right]}{\left[1-\left(q_{1}-q_{2}\right)^{2}\right]\left[H_{1}-\mu_{2}\right]}>0 \\
& \lim _{n \rightarrow \infty} \hat{\beta}_{2}=\frac{\left(\theta_{1}-\theta_{2}\right)+\left(\phi_{1}-\phi_{2}\right)\left(q_{1}-q_{2}\right)}{\left(q_{1}-q_{2}\right)\left(H_{1}-\mu_{2}\right)}>0
\end{aligned}
$$

In large samples, we would therefore reject the null hypothesis $H_{0}: \beta_{2}=0$, implied by the Lucas-type theories. This is in fact the result obtained by Mishkin (1982).

\section{Monetary Cycles}

If our model were subjected to monetary disturbances, i.e. fluctuations in the quantity of outside (fiat) money, would it exhibit comovements among aggregate variables which mimiced features of the data as well as did the 'real cycle' model in the previous section? The answer is no, and this conclusion is robust with respect to changes in the type of fiat money stock process we consider.

As was indicated in the previous section, unanticipated one-time changes in the stock of fiat money are neutral in the model; the price level simply rises in proportion. For fiat money to be nonneutral here, current changes in 
its stock must signal future changes, since such signals provide information on the intertemporal terms of trade. Suppose then, that the model is subjected to monetary disturbances and that there are no real disturbances. Then, in states where agents anticipate a low return on fiat money (and, in equilibrium, a low return on intermediary deposits), the quantity of loans will be high and employment and savings will be low. Business failures will be low next period. Therefore, low employment will be associated with a high quantity of loans and a low level of business failures, which is inconsistent with what we observe. This argument depends in no way on the characteristics of the stochastic process that fiat money follows. We only require that the current stock of fiat money aids in predicting future money growth.

\section{An Example}

Consider the example in section 3 , page 15 , with $\alpha=.5$ and $h=3$. Also, assume that the stock of fiat money follows a two-state Markov process. I.e., letting $s_{t}$ denote the state, the stock of fiat money is $H$ if $s_{t}=1$ and $z H$ if $s_{t}=2$, where $z>1$. Changes in the fiat money stock are effected through transfers to old type 1 agents. ${ }^{10}$ The state evolves in the same manner as was specified in section 4 . We let $H=1, z=1.05$, and $q_{1}=$ $q_{2}=.5$.

An equilibrium solution is then: $p_{1}=.1468, p_{2}=.1458, c_{1}^{*}=4.007$, $c_{2}^{*}=3.993, x_{1}^{*}=3.993, x_{2}^{*}=4.007, L_{1}=.3497, L_{2}=.3491, \ell_{1}=1.003$, $\ell_{2}=.997, s_{1}=.993, s_{2}=1.007, K_{1}=6.764, K_{2}=6.908$. Note in particular that, while employment, the nominal money supply and the price level are lower in state 1 than in state 2, the aggregate quantity of loans is higher. Calculating the large sample theoretical covariance between the nominal monetary aggregate and loans, using (4.13), we get $\operatorname{cov}\left(\mathrm{M}_{t}, \mathrm{~L}_{t}\right)=-2.304 \mathrm{x}$ $10^{-5}$. This is clearly inconsistent with what we observe. Note also that, 
since agents face a lower expected rate of return in state 1 than in state 2 , that business failures will be lower following state 1 than following state 2. Money and business failures will be negatively correlated, which is again inconsistent with observation.

If our model were subjected to real disturbances of the type considered in the previous section, in addition to independent monetary disturbances, then real disturbances would have to be "large" relative to monetary disturbances for the model to mimic the aggregate comovements which are observed in the data. In this sense, our model lends support to real business cycle theory at the expense of monetary theories of the business cycle.

\section{Summary and Conclusion}

In this paper we have constructed a business cycle model which, when subjected to disturbances in the riskiness of investment projects, displays comovements among real output, intermediary loans, a nominal monetary aggregate, the price level, business failures and risk premia, which qualitatively mimic what we observe. In contrast to this "real business cycle", a monetary business cycle in the model would produce comovements in aggregate time series which are inconsistent, in several respects, with observation. This provides support for real business cycle theory at the expense of monetary theories of the business cycle.

our framework is novel in that it provides an explanation for fluctuations in business failures and risk premia over the cycle. Financial intermediation in the model arises endogenously as a means of economizing on monitoring costs and making optimal contracts feasible. In equilibrium, there is a credit supply effect, in that some would-be borrowers do not receive loans, in spite of the fact that they would be willing to pay higher-than-market interest rates to bid loans away from those who do receive 
them. The amount of "credit rationing" which occurs varies over the cycle, and this effect complements an intertemporal substitution mechanism in producing fluctuations in real output. In fact, the model would display most of the observed comovements in aggregate time series in the absence of any intertemporal substitution effect.

A criticism of real business cycle models, such as Kydland and Prescott (1982), is that they do not explain unemployment or fluctuations in the unemployment rate. Though our model has focused mainly on credit market behavior, it could be the object of the same criticism, i.e., there is no unemployment of labor, as such, in the model, and changes in "employment" result from changes in desired leisure in response to changes in intertemporal rates of return. However, if we interpret "unemployment" sufficiently broadly, the model exhibits involuntary unemployment of resources in each period in equilibrium, in that type 2 agents who do not receive loans would rather by operating their projects, given market interest rates, than doing nothing. It may be possible to modify the model so that this looks more like unemployed labor, and we would then have an unemployment rate which varied countercyclically in response to real disturbances.

To this point nothing has been said about the optimality or non-optimality of equilibrium in the model, or the possibility of a role for government intervention. It would be quite difficult to do rigorous welfare analysis with the model, since this is complicated by the existence of private information in addition to intragenerational heterogeneity and an overlapping generations structure. There seems to be no obvious role for the government here, and there is nothing about the existence of credit rationing in the model which would lead us to believe that "stabilization policy" in some form might prove beneficial. To answer these welfare questions would require further research. 


\section{Appendix}

\section{Proof of the Optimality of Debt Contracts}

The following is adopted from Williamson (1984). We assume that an intermediary has sufficient type 1 agents as depositors that the total quantity of deposits is an integer and that monitoring is costless within an intermediary. We ignore nonnegativity constraints on total consumption by the intermediary coalition. Since type 2 agents born in the current period are identical except for their monitoring costs, the contracts offered will depend only on c. If a given type 2 agent's project is funded by the intermediary, the contract specifies that one unit of the consumption good will be transferred to the type 2 agent in the current period $t$. The contract also must specify the payment to be made to the intermediary in period $t+1$ in the event that the intermediary monitors the borrower, and in the event that monitoring does not occur.

In period $t+1$, the project return, $w$, is realized, and the type 2 agent emits some signal $w^{d}$ to the intermediary where $w_{\varepsilon}^{d}[0, \bar{w}]$. The contract. will specify that, if $w^{d} \in s \subset[0, \bar{w}]$, then monitoring occurs and if $w^{d} \neq s$, then monitoring does not occur. The payment from the type 2 agent to the intermediary will then be:

$$
R= \begin{cases}R(w), & w^{d} \varepsilon s \\ K\left(w^{d}\right), & w^{d} \notin s\end{cases}
$$

If $w^{d} \notin s$ then the type 2 agent will always choose $w^{d *}=\underset{\{w \in s\}}{\operatorname{argmin}} K\left(w^{d}\right)$. 
Therefore, when $w^{d} \notin s$, the payment from the type 2 agent to the intermediary will be some constant, $x$.

The payment schedule must satisfy the following feasibility conditions:

$$
0 \leq R(w) \leq w
$$

Incentive compatibility implies that:

$$
\begin{aligned}
& w^{d} \in S \text { if } R(w)<x \\
& w^{d} \notin s \text { if } R(w)>x \\
& w^{d} \in S \text { or } w^{d} \notin s \text { if } R(w)=x
\end{aligned}
$$

Let $A=\{w: R(w)<x\}$ and $A^{C}=\{w: R(w) \geq x\}$. Then, the optimal contract is a payment schedule-"interest rate" pair $(R(w), x)$ which maximizes the expected return to the type 2 agent subject to the constraint that the expected return to the intermediary be at least $r_{t}$, the expected market return. That is, we solve:

$$
\begin{aligned}
& \max _{(R(w), x)} \int_{A}[w-R(w)] f(w) d w+\int_{C}(w-x) f(w) d w \\
& \text { subject to: } \quad\left\{[R(w)-c] f(w) d w+\int_{c} x f(w) d w \geq r_{t}\right.
\end{aligned}
$$

Proposition: The optimal payment schedule is $R(w)=w$, independent of $x$.

Proof: Suppose that the proposition does not hold, and that $\left(R^{\prime}(w), x^{\prime}\right)$ is the optimal contract. First, note that the constraint in (A.1) must hold with equality, since if this were not so, we could decrease $R(w)$ for some $w$ such that the constraint would still hold, and increase the value of the objective 
function. We therefore have:

$$
\begin{aligned}
& \int_{A^{\prime}}\left[R^{\prime}(w)-c\right] f(w) d w+\int_{A^{\prime}} c^{x^{\prime} f(w) d w=r_{t}} \\
& A^{\prime}=\left\{w: R^{\prime}(w)<x^{\prime}\right\} A^{\prime}=\left\{w: R^{\prime}(w) \geq x^{\prime}\right\}
\end{aligned}
$$

Now, consider another payment schedule $R^{\prime \prime}(w)$ with $R^{\prime \prime}(w) \geq R^{\prime}(w)$ for all $w \in[0, \bar{w}], R^{\prime \prime}(w)>R^{\prime}(w)$ for some $w \in A^{\prime}, R^{\prime \prime}(\cdot)$ continuous and monotone increasing on $[0, \bar{w}]$, Then there is some $x^{\prime \prime}$ with $0<x^{\prime \prime}<x^{\prime}$ such that

$$
\begin{aligned}
& \left\{_{A^{\prime \prime}}\left[R^{\prime \prime}(w)-c\right] f(w) d w+\int_{A^{\prime \prime}} x^{\prime \prime} f(w) d w=r_{t}\right. \\
& A^{\prime \prime}=\left\{w: R^{\prime \prime}(w)<x^{\prime \prime}\right\} ; A^{\prime \prime}=\left\{w: R^{\prime \prime}(w) \geq x^{\prime \prime}\right\}
\end{aligned}
$$

The change in the objective function in changing the contract from $\left(R^{\prime}(w), x^{\prime}\right)$ to $\left(R^{\prime \prime}(w), x^{\prime \prime}\right)$ is then given by:

$$
c\left[\int_{A^{\prime}} f(w) d w-\int_{A^{\prime \prime}} f(w) d w\right]>0
$$

since $R^{\prime \prime}(w) \geq R^{\prime}(w)$ and $x^{\prime}>x^{\prime \prime}$ imply that $A^{\prime \prime} C A^{\prime}$ and $A^{\prime}-A^{\prime \prime} \neq \phi$. Therefore, the objective function can be increased with the constraint still holding, which implies that $\left(R^{\prime}(w), x^{\prime}\right)$ is not the optimal contract, a contradiction. Q.E.D. Given proposition 1 , optimal contracts are standard debt contracts. 


\section{Footnotes}

${ }^{1}$ of course, there has been much equilibrium business cycle modelling in the Lucas mold that is not so explicit. One example is Barro (1976).

${ }^{2}$ Credit rationing results here, and in Williamson (1984, 1985) for quite different reasons than those studied by Keeton and stiglitz and Weiss. In the work of those quthors, this type of credit rationing occurs due to adverse selection in credit markets or ex ante moral hazard, neither of which is a factor here.

${ }^{3}$ A similar assumption is made in Lucas (1972). This assures that leisure decreases and savings increases with an increase in the expected rate of return faced by the agent.

${ }^{4}$ We assume that agents have recourse to a costless legal system which enforces contracts. Note that the court does not need to observe project returns. It need only verify that contract terms are met and enforce property rights.

${ }^{5}$ stiglitz and Weiss (1981), for example, argue that we do observe such phenomena.

${ }^{6}$ The example also illustrates that the stationary monetary equilibrium may not exist. This feature is common to other overlapping generations models with intragenerational trade. Also, given the form of type 1 agents' utility functions, they may choose $s_{t}=0$ if $r_{t}$ is low enough; in which case the demand for all assets is zero.

${ }^{7}$ It may or may not be the case that the number of bankruptcies (or the bankruptcy rate) is greater following the occurence of state 2 than following state 1. While the probability of bankruptcy for a type 2 agent is higher in 
state 2 than in state 1 , holding $Y$ constant, more projects are funded in state 1 than in state 2 , and these marginal projects have the highest probability among funded projects of going bankrupt.

8 Arguably, this is what we mean by a Phillips curve. This appears to be the correlation that econometric model builders attempt to capture in wage and price equations.

${ }^{9}$ Note, however, that state contingent changes in the supply of fiat money would have real effects, since this would change anticipated real rates of return in equilibrium. We discuss this type of monetary cycle in section 5.

${ }^{10}$ Transfers therefore do not affect behavior. Wote that if transfers went to type 2 agents, this would change the form of loan contracts. 


\section{References}

Barro, R. (1976), "Rational Expectations and the Role of Monetary Policy," JME 2 .

(1977), "Unanticipated Money Growth and Unemployment in the U.S.," American Economic Review, March.

Bernanke, B. (1981), "Bankruptcy, Liquidity and Recession," American Economic Review 71 , no. 2, 155-59.

(1983), "Nonmonetary Effects of the Financial Crisis in the Propagation of the Great Depression," American Economic Review 73, no. $3,257-76$.

Boyd, J. and E. Prescott (1985), "Financial Intermediary Coalitions," Working Paper \$272, Federal Reserve Bank of Minneapolis.

Diamond, D. (1984), "Financial Intermediation and Delegated Monitoring," Review of Economic Studies $60,393-414$.

Fiedler, E. (1971) Measures of Credit Risk and Experience, National Bureau of Economic Research, New York.

Freeman, S. (forthcoming), "Inside Money, Monetary Contractions and Welfare," Canadian Journal of Economics.

Friedman, M. and A. Schwartz (1963), "A Monetary History of the United States, 1867-1960," NBER Studies in Business Cycles, No.12, Princeton.

Gale, D. and M. Hellwig (1984), "Incentive-Compatible Debt Contracts: The One-Period Problem," Working Paper, London School of Economics.

Geweke, J., Meese, R. and W. Dent (1983), "Comparing Alternative Tests of Causality in Temporal systems: Analytic Results and Experimental Evidence," Journal of Econometrics 21 , no. 2, 161-94.

Keeton, W. (1979), Equilibrium Credit Rationing, New York, Garland Press. 
King, R. and C. Plosser (1984), "Honey, Credit and Prices in a Real Business Cycle," American Economic Review 74, no. 3, 363-80.

Kydland, F. and E. Prescott (1982), "Time to Build and Aggregate Fluctuations," Econometrica 50, no. 6, 1345-70.

Litterman, R. and T. Weiss, (1985), "Koney, Real Interest Rates and output:

A Re-interpretation of Post-War U.S. Data," Econometrica 53, no. 1, 129-56.

Long, J. and E. Plosser (1983), "Real Business Cycles," Journal of Political Economy 91 , no. 1, 39-69.

Lucas, R. (1972), "Expectations and the Neutrality of Money," Journal of Economic Theory 4, 103-124.

(1973), "Some International Evidence on Output-Inflation Tradeoffs," American Economic Review 63, 326-34.

(1981), "Understanding Business Cycles," reprinted in Studies in

Business Cycle Theory, urT Press, Cambridge, MA.

Mishkin, F. (1982), "Does Unanticipated Money Matter? An Econometric Investigation," Journal of Political Economy 90, no. 1, 22-51.

Moore, G. and P. Klein (1967), The Quality of Consumer Installment Credit, NBER, New York.

Prescott, E. (1983), "Can the Cycle be Reconciled with a Consistent Theory of Expectations? or A Progress Report in Business Cycle Theory," Working Paper \#239, Federal Reserve Bank of Minneapolis.

Rothschild, M. and J. Stiglitz (1970), "Increasing Risk: 1. A Definition," Journal of Economic Theory 2, 225-43. 
(1982), "The Real Bills Doctrine versus the Quantity Theory: A Reconsideration." Journal of Political Economy 90, no. 6, 1212-36.

Sims, C. (1972), "Money, Income and Causality," American Economic Review 62 540-52. (1980), "Comparison of Interwar and Postwar Business Cycles: Monetarism Reconsidered," American Economic Review 70, no. 2, 250-57.

Smith, B. (1985), "Unemployment, the Variability of Hours and the Persistence of 'Disturbances': A Private Information Approach," Working Paper \#279, Federal Reserve Bank of Minneapolis.

Stiglitz, T. and A. Weiss (1981), "Credit Rationing in Markets with Imperfect Information." American Economic Review, 393-410.

Tobin, J. (1970), "Honey and Income: Post Hoc Ergo Propter Hoc?" Quarterly Journal of Economics $84,310-17$.

Williamson, S. (1984), "Costly Monitoring, Loan Contracts and Equilibrium Credit Rationing," Discussion Paper $\$ 572$, Queen's University Institute for Economic Research.

(1985), "Costly Honitoring, Financial Intermediation and Equilibrium Credit Rationing," Working Paper, Queen's University. 